Chirurgia (2017) 112: 503-504

No. 5, September - October

Copyright@ Celsius

http://dx.doi.org/10.21614/chirurgia.112.5.503

\title{
Emergency Surgery in Romania - Present and Perspectives!
}

\author{
Mircea Beuran ${ }^{1,3}$, Bogdan Diaconescu ${ }^{2,3}$ \\ 'ESTES Congress President 2017; ' 2 ESTES Congress Co-President 2017 \\ ${ }^{3}$ Carol Davila University of Medicine and Pharmacy, Emergency Hospital of Bucharest, Romania
}

Corresponding author:

Mircea Beuran, MD, PhD, FACS

Professor of Surgery

Carol Davila University of Medicine and Pharmacy Bucharest - President of the University Senate

Emergency Hospital of Bucharest,

Romania

E-mail: drmirceabeuran@yahoo.com
Traumatic injuries represent the most common cause of death in the younger population under age 40. Nowadays we are facing an increasing mortality rate among trauma patients. Many of the deaths take place in the pre-hospital setting, within minutes, usually at the site of the accident. These can be avoided by national promotion and implementation of preventive measures. The second peak of mortality for injured patients, according to the classical model proposed by Donald Trunkey, occurs within the first hours and represents $30 \%$ of deaths. These patients are highly dependent on functional trauma systems, their rescue being possible by a 'scoop and go' policy of prehospital care and specially designed trauma centers. For these patients, we have the 'platinum ten minutes' and the 'golden hour', during which the hemorrhage should be stopped. These two intervals of time suggest the level of performance required for a modern trauma system.

There is no doubt that worldwide, surgery is going to subspecialization, significant economic resources being dedicated to such units. On the other hand, the national policies fail in offering enough high-quality trauma and acute care surgeons. Currently, young surgeons are managing trauma and other acute patients, with major anatomical and physiological disturbances, just because of a contractual obligation.

The situation in Romania is very similar to other European countries. In Bucharest, there are four new hospitals who developed emergency departments. The emergency hospitals from Bucharest, together with the county hospitals have founded the Romanian Society for Trauma and Emergency Surgery. In the latest five years, the society understood the 
lack of standardization in medical care and tried to develop the guidelines for trauma and emergency surgery, together with European Society for Trauma and Emergency Surgery. We all understood the major national needs for education and training. The Emergency Hospital of Bucharest, in cooperation with Carol Davila University of Medicine and Pharmacy, settled an intense program for training, with hands-on courses for trauma and emergency surgery. The hands-on training was realized for open and minimally invasive approaches. Although initially not a sterile field, the laparoscopy started to play an increasing role, as a diagnostic and therapeutic tool, in emergency conditions. It does not surprise the continuous upward trend of laparoscopic emergency surgery. The General Surgery Department of the Emergency Hospital of Bucharest developed a working group with MedUni Graz, Austria and Humanitas Milano from Italy. The workshops for trauma and emergency surgery are very well appreciated. All these courses are endorsed by the European Society of Trauma and Emergency Surgery and European Association of Endoscopic Surgery. During the latest three years, these workshops were attended by international colleagues.

The medical performance of the surgical team is the cornerstone of treatment for acute patients. However, should be emphasized that emergency patients require significantly other resources. The Romanian Society for Trauma and Emergency Surgery supported the implementations of a National Program for Trauma and Acute Care Surgery. Unfortunately, this program was not a priority for the Ministry of Health during the latest two years. This is opposite to the Western countries, United Kingdom and Germany for example, which identified their major problems in the management of emergency patients.

The emergency patients require significant financial and human resources during their first 24 hours of care. If lost, the burden for the healthcare system increases exponentially, with high morbidity, mortality and low quality of life. Significant improvements were obtained by the National Program of Intensive Care. Unfortunately, this program does not include any surgical device for trauma and acute care patients.

In the end, we are full of hope that trauma and emergency surgery will become a national priority. Only through mid- and long-term healthcare policies, at a national level, we may offer to the Romanian people best medical care. We should not forget that trauma is responsible for most of the years of potential life lost, 22 times more than heart diseases and two times more than cancer. 